\title{
The Disposition of the Human Pelage
}

\author{
G.H. Sperber \\ Faculty of Medicine \& Dentistry \\ University of Alberta, Edmonton, Canada
}

\begin{abstract}
:
A brief review of the origin, disposition and various anomalous conditions of human hair. The forms of hair vary from fine lanugo to vellus hair to terminal coating. The fate and disposition of various forms of hair at different ages are subject to genetic determination, full details of which are yet to be identified. The retention, arrangement and display of human hair constitutes a major feature of adornment, pulchritude, cosmetology and of religious portrayal. The loss of scalp hair leading to baldness is a significant socio-insalubrity occupying those afflicted. The "cure" or amelioration of baldness is a much sought after project by geneticists and clinicians.
\end{abstract}

Keywords: Trichology; Pelage; Whiskers; Eyelashes; Alopecia; Baldness; Neurocristopathy.

\section{INTRODUCTION}

Of all the characteristics of the human physiognomy, none is more conspicuous than the presence, disposition or absence of hair. The significance of perceptions of hair as a sociological portrayal cannot be overestimated. Hair as the most conspicuous appendage of epithelium has evolved as a constituent of a diverse array of topics ranging from sociology to dermatology. That hair is hygroscopic (tending toward retaining moisture) is a feature that means it changes its length with variation in humidity. This characteristic been employed in hygrometers, whereby hair length under tension can be calibrated to reveal the degree of ambient humidity.

Hair follicle morphogenesis is initiated by a dermal signal of WNT inducing follicle development in the overlying epithelium. Dickkopf 1 inhibits WNT action, accounting for hairlessness (1).

Development of hair as a protective pelt is a thermoregulatory appendage to maintain a normal temperature of 37 degrees $\mathrm{C}$. Temperature maintenance is a balance between the thermogenetic (heat production) and the thermolytic process of heat dispensation. Clearly, hair is indispensably intertwined with thermoregulation. The action of the erector pili in raising hairs when cold or to emotional responses indicative of hair's integration with physiology and endocrinology.

Hair is first manifest as lanugo in the developing fetus, where it forms on the back as a fur more dense than that of the gorilla and chimpanzee at a similar fetal stage and reflecting evolutionary conservatism in embryogenesis. However, the relative hairlessness of humans is the result of the gene for keratin formation, the major protein of hair, while expressed in chimpanzees, is silenced by a genetic stop codon in the human genome. This evolutionary mutation allowed for greater body cooling when early hominins descended from the trees to open plains, evolving the naked ape $(2,3)$. The consequent requirement for replacement of the lost protective coating gave rise to the whole garment and fashion industries.

The lanugal hairs of the in utero fetus are mostly shed before birth, to be replaced by vellus hair, the downy epidermal growth in infancy and childhood. The terminal hair that finally overgrows and replaces vellus hair at puberty is androgenically driven and characteristically appears over the scalp, in the face as eyebrows, a beard and moustache, in the armpits and pubes, marking adolescence. The retention of terminal hair in these particular locations is genetically determined, but has not yet been established. The purposes served by the hairs in these restricted locations are the subject of much 


\section{G.H. Sperber, "The Disposition of the Human Pelage"}

speculation. The virility of males has been judged on the basis of their hair growth and provided the mythical strength of the biblical Samson. The cutting of his hair by Delilah deprived him of his strength, but its regrowth revived his legendary strength. The prohibition of shaving or cutting hair is the edict of certain religions. The areas devoid of hair, the palms of the hands and soles of the feet, the flexor surfaces of digits, the ears, scrotum, penis, clitoris, lips, labia majora and minora pudenda, female breast and nipple necessarily inhibit hair growth, the genetic basis of which is currently unknown. Hair density varies from $>600$ per $\mathrm{cm} 2$ on the face to 60 per $\mathrm{cm} 2$ on the rest of the body. Except for head and face hairs, most body hairs grow to a predictable length, and are shed periodically to be replaced by new hairs of the same length. Hair does not grow continuously but intermittently. It is the exceptional, although intermittent, continuous growth of the craniofacial pelage that provides for the rationale of barber's shavings and hairdresser's cutting capabilities.

Eyelashes, eyebrows, nostril and external auditory hairs and those around the anogenital orifices serve as protective webs against foreign body intrusions. The tactile vibrissae of rodents and cats and dogs serve as special sensory organs and as protective devices.

The biomonitoring of hair for trace elements can provide a public health metric for environmental pollution (4). The role of hair a source of forensic information is of especial significance in its capacity to reveal embedded chemical components of the victims of crime. Sophisticated spectroscopic analysis is increasingly being employed using attenuated total reflection Fourier transform infrared examination of hair samples (5).

The susceptibility of hair growth to cancer chemotherapeutic regimens, resulting in hair loss, is a major concern of oncologists and their patients. Scalp hair is in a category on its own by virtue of its consistency, color and as a fashion statement. Scalp hair may even grow in utero towards the end of gestation, and present as a full head of hair at birth. The subsequent treatment of hair growth is subject to the dictates of religion, fashion and the tonsorial profession. It is the maintenance of scalp hair and its diminishment, predominantly in males, that leads to baldness that is one of the major mysteries of trichology and a factor of great sociological significance. While the hormonal influences on hair growth are well known $(6,7)$, the genetic factors determining the location and characteristics of pelage distribution are largely unknown.

The genetic determination of hair color by graded doses of melanin deposition in the hair root is well established. Black hair results from extensive deposition of melanin in the hair root that diminishes with age, and leads to the greying of the hair. Lack of melanin occurs in natural blond hair, but albinism is a genetically determined inborn amino acidopathy affecting melanocytes impacting eyes, skin and hair. Red hair occurring in 1-2\% of the population is the result of two copies of a recessive allele, creating an ethnic characterization. However, the pathological red hair appearing in malnourished infants as a result of severe protein deficiency is pathognomonic of a clinical condition known as kwashiorkor.

Clinical conditions afflicting hair occupy trichologists that range from ectodermal dysplasias expressing hairlessness to hyperhidrosis and hirsutism displaying excessive hairiness [8].

The pattern of hair loss in alopecia areata is largely confined to the frontal area of the scalp. The identification of the genes leading to baldness provides the potential to genetically intervene in their expression $[9,10,11]$. Accordingly, the possibility of preventing or ameliorating scalp hair loss by gene editing techniques would be one of the most welcomed advances in gene therapy for a genetically determined condition that afflicts millions of sufferers. The "cure" for baldness would be a landmark advancement of anticipated preventive gene therapy. Focusing on the genetic determination of the frontal ectomesenchyme might lead to identifying the phenotypic expression of baldness.

Baldness may be a component of the wide spectrum of neurocristopathies (12). The boundary of embryonic neural crest expression in the frontal region coincides with the site of hair loss in baldness (13). Future research in embryogenetics and endocrinology will provide the answers to present clinical concerns. The topography of hair distribution and its consequences will remain central themes of medical and social interest for much of the future. 


\section{REFERENCES}

[1] T. Andi, S.T. Reddy, T. Gaddapara, S.E. Miller. "WNT signals are required for the initiation of hair follicle development." Dev Cell 2(5). Pp. 643-653, 2002.

[2] D. Morris. The Naked Ape. London: Cape, 1967.

[3] G. Santpere, M. Lopez-Valenzuela, N. Petit-Marty, A. Navarro, Y. Espinosa-Parrilla. "Differences in molecular evolutionary rates among microRNAs in the human and chimpanzee genomes." BMC Genomics 17(1) art. no. 528. 2016. DOI: 10.1186/s12864-016-2863-3.

[4] E.J. Drobyshev, N.D. Solovyev, N.B. Ivanenko, M.Y. Kombarova, A.A. Ganeev. "Trace elements biomonitoring in hair of school children from a polluted area by sector field inductively coupled plasma mass spectrometry”. Jnl Trace Elements Med Biol 39, pp.14-20. 2017.

[5] J. Manheim, K.C. Doty, G. McLaughlin, I.K. Lednev. "Forensic hair differentiation using attenuated total reflection Fourier Transform Infrared (ATR FT-IR) spectroscopy" Applied Spectroscopy 70(7) pp. 1109-1117. 2016.

[6] Y. Shimomura. "Journey toward unraveling the molecular basis of hereditary hair disorders". Jnl Dermatol Sc. 2016. DOI: 10.1016/jdermsci.2016.08.006.

[7] M.L. Batrinos. "The endocrinology of baldness", Hormones. 13(2) pp.197-212. 2014.

[8] J.C. Vary Jr. "Selected disorders of skin appendages- acne, alopecia, hyperhidrosis". Med Clin N Am 99:pp. 1195-1211. 2015.

[9] J.B. Richards, X. Yuan, F. Gelier et al. "Male pattern baldness susceptibility locus at 20p11". Nat Genet 40 (11) pp. 1282-1284. 2008.

[10] F.F.Brockschmidt, S. Heilmann, J.A. Ellis et al. "Susceptibility variants on chromosome 7p21.1 suggest HDAC9 as a new candidate gene for male-pattern baldness". Brit Jnl Dermatol 165(6) pp.1293-1302. 2011.

[11] S. Heilmann-Heimbach, L.M. Hochfeld, R. Paus, M.M. Nothen. "Hunting the genes in malepattern alopecia: how important are they, how close are we and what will they tell us?" Experimental Dermatol. 25pp.251-257. 2016.

[12] R.P. Bolande. "The neurocristopathies". Hum Path 5: pp 409-429. 1974.

[13] R.A. Deckelbaum, G. Holmes, Z. Zhao, C. Tong, C. Basilico, C.A. Loomis. "Regulation of cranial morphogenesis and cell fate at the neural crest-mesoderm boundary by engrailed 1". Development 139: pp.1346-1358. 2012.

Citation: G. H. Sperber. The Disposition of the Human Pelage. International Journal of Research Studies in Medical and Health Sciences. 2016;1(1):23-25.

Copyright: (C) 2016 G. H. Sperber. This is an open-access article distributed under the terms of the Creative Commons Attribution License, which permits unrestricted use, distribution, and reproduction in any medium, provided the original author and source are credited. 